\title{
Mesenchymal Stem Cells Support Proliferation and Terminal Differentiation of B Cells
}

\author{
Yue Ru Jia Zhou Xin Yang ${ }^{a}$ Zhi-Bo Han ${ }^{a, b}$ Lei Meng ${ }^{a, b}$ Lu Liang ${ }^{c}$ Xiao Ming Feng ${ }^{a}$ \\ Shao Guang Yanga Ying Chi ${ }^{a}$ Dan Dan Chen ${ }^{a}$ You Wei Wanga,c Zhong Chao Han ${ }^{a, b, c}$
}

\begin{abstract}
aThe State Key Laboratory of Experimental Hematology, Institute of Hematology and Hospital of Blood Diseases, Chinese Academy of Medical Sciences and Peking Union of Medical College, Tianjin, China; bNational Stem Cell Engineering Research Center, TEDA, Tianjin, China; 'National Engineering Research Center of Cell Products, AmCellGene Co. Ltd, Tianjin, China
\end{abstract}

\section{Key Words}

Mesenchymal stem cells • B cells • PGE2 • IL-6

\begin{abstract}
Background: Mesenchymal stem cells (MSC) play important roles in modulating the activities of T lymphocytes, dendritic cells and natural killer cells. These immunoregulatory properties of MSC suggest their therapeutic potential in autoimmune diseases. However, the effects of MSC on B cells are still poorly understood. The present study was designed to investigate the interaction between MSC and B cells both in vitro and in vivo, and to determine the possible mechanism of action. Design and Method: The effect of human umbilical cord mesenchymal stem cells (UC-MSC) on proliferation and differentiation of B-cells were characterized in vitro, and we also tested the immunoregulatory properties of mouse bone marrow MSC (BM-MSC) on T cell dependent and independent antibody production in vivo in mice. Results: Treatment with human UC-MSC resulted in an increase of proliferation, differentiation of B cells into plasma cells and production of antibodies in vitro. Mouse BM-MSC significantly enhanced $\mathrm{T}$ cell dependent and independent antibodies production in vivo in mice. PGE2 partially mediated the immunosuppressive activity of human UC-MSC but IL- 6 did not regulate this activity. Conclusion: MSC promote proliferation and differentiation of B cells in vitro and in vivo partially through PGE2 but not IL-6.
\end{abstract}




\section{Introduction}

Mesenchymal stromal cells (MSC), initially described by Friedenstein in 1970 [1], can be obtained from a variety of tissues, including bone marrow (BM-MSC), adipose (AD-MSC) [2], umbilical cord blood (UCB-MSC) [3], placenta [4], umbilical cord (UC-MSC) [5], amniotic fluid (AF-MSC) [6] and many other tissues [7]. MSC affect both the phenotype and the function of a number of cells that belong to the innate and adaptive immune system including $\mathrm{T}$ and $\mathrm{B}$ lymphocytes, dendritic cells, and natural killer cells [8]. In addition, their immunomodulatory effects have been tested in a variety of animal models related to alloreactive immunity (GVHD) [9], autoimmune diseases such as experimental autoimmune encephalomyelitis (EAE) [10], collagen-induced arthritis (CIA) [11], systemic lupus erythematosus (SLE) [12], and systemic sclerosis (SSc) [13]. Actually, human UC-MSC are being explored as a promising candidate for many potential clinical applications due to their easy isolation and expansion in large quantities [5], and to their immunosuppressive effect on T cells [14, 15]. We have previously demonstrated that UC-MSC exert their immunosuppresion via IL-1 $\beta$-PGE2 axis $[14,16]$. However, the clinical application of MSC was focused on TH1 type autoimmune diseases such as collagen induced arthritis $[11,17]$, experimental autoimmune encephalomyelitis [10] and type 1 diabetes mouse models [18]. Th1 cells are able to promote cell-mediated immunity and Th2 response is often associated with the humoral response. MSC ameliorated the clinical and histopathological severity of autoimmune diseases through down-regulation TH1 responses [19] and activation of CD4+CD25+FoxP3+ Tregs [20]. However, allogeneic MSC did not benefit New Zealand black (NZB) X New Zealand white (NZW) F1 (NZB/W) mice and appeared to exacerbate systemic lupus erythematosus (SLE) which belonged to TH2type SLE [21]. MSC supported in vitro proliferation and differentiation to immunoglobulinsecreting cells (ISCs) of B cells isolated from SLE patients [22].

B cells play an important role in autoimmune diseases both as immunoglobulin-secreting cells and regulatory cells to product cytokines, which influence T cells, macrophages, natural killer cells in the pathogenesis of autoimmunity disease [23]. B-cell development occurs in the bone marrow and is strictly dependent on close interaction between B-cell progenitors and stromal cells that produce cytokines capable of supporting B-cell survival and proliferation. However, there is no further information on the immunomodulation effects of MSCs on antibodies production in vivo.

In this study, we investigated the immunomodulation effect of human UC-MSCs on the in vitro proliferation and differentiation of B cells into immunoglobulin-secreting cells and the possible mechanism, and we also tested mice BM-MSC on T cell dependent and independent humoral immunity in mice vivo, and we found that human UC-MSC promote B cell proliferation and differentiation in vitro partially though PGE2 but not IL-6, mice BM-MSC increased the T cell dependent and independent IgM and IgG production in vivo. Our results suggest that MSC promote humoral immunity both in vitro and in vivo partially though PGE2 but not IL-6. This study raise important questions on MSC as a therapeutic tool in some autoimmune diseases especially associated with auto-antibodies.

\section{Materials and Methods}

\section{Human UC-MSC and murine bone marrow MSC preparation}

Human UC-MSC were isolated from umbilical cords obtained from local maternity hospitals with donors' informed consent. Human tissue collection for research was approved by the institutional review board of the Chinese Academy of Medical Science and Peking Union Medical College. UC-MSC isolation and ex vivo expansion were done according to the procedures described previously [5]. UC-MSC were negative for CD3, CD14, CD19, CD34, CD45, CD31, CXCR4, Stro-1, HLA-DR, CD80, and CD86 expression but positive for CD13, CD44, CD73, CD90, CD105, CD106, CD166, CD29, CD49e, and HLA-ABC expression (data not shown). In addition, UC-MSC were able to differentiate into adipogenic, osteogenic and chondrogenic cells in lineage-specific induction conditions as previously described [14]. UC-MSC at passage 4-6 were preplated 
and subjected for 30 Gy irradiation and then allowed to adhere 2 hours at $37^{\circ} \mathrm{C}$ before co-culture with B cells.

Murine MSC were isolated from bone marrow BALB/c mice. The whole BM cells were flushed out of the mouse femur and tibia, and cultured in $25 \mathrm{~cm}^{2}$ tissue culture flasks $\left(5 \times 10^{5} \mathrm{cells} / \mathrm{cm}^{2}\right)$ using L-DMEM (Gibco) containing 10\% FBS, 5ng/ml recombinant murine FGF-basic (Peprotech), and 20ng/ml mouse $\mathrm{EGF}$ (Peprotech) at $37^{\circ} \mathrm{C}$ in air plus $5 \% \mathrm{CO}_{2}$ and $5 \% \mathrm{O}_{2}$. After 3 day culture, the nonadherent cells were decanted by changing the medium. The adherent cells were trypsinized and replated at 1:3 ratio when cultures reached $70 \%$ to $80 \%$ confluence. After two passages, the cells were harvested and stained with fluorescein-conjugated monoclonal antibody against CD14, CD19,CD29, CD45, CD80, and HLA-DR, CD90 (biolegend) and the flow cytometry analysis was performed on a FACSCalibur using the CellQuest software (Becton Dickinson).The capacity of BM-MSC that differentiate along adipogenic and osteogenic lineages was also evaluated following the supplier's instruction by Adipogenesis Differentiation Kit and Osteogenesis Differentiation Kit (Gibco). BM-MSC were negative for CD14, CD19, CD45, CD80 HLA-DR expression but positive for CD90, CD29 expression (data not shown).

\section{Flow Cytometry Analysis}

Phycoerythrin (PE)-CD19,-CD138, were purchased from Becton Dickinson(BD). $1^{*} 10^{5}$ B cells were harvested, washed once with and resuspended in PBS. Cells were treated at RT for 30 min with the isotype control mAbs or with the following specific anti-human antibodies, and flow cytometry analysis was performed on a FACSCalibur using the CellQuest software (Becton Dickinson).

\section{$B$ Cells Isolation and Culture}

Peripheral blood samples were generated from healthy donors after informed consent was obtained. Peripheral blood mononuclear cells were isolated by Ficoll-Hypaque (Axis-Shield) density gradient centrifugation. CD19 ${ }^{+} \mathrm{B}$ cells were isolated using CD19 microbeads (Miltenyi Biotec) according to the manufacturer's instructions. Briefly, the PBMC were magnetically labeled with CD19 microbeads, and then loaded onto the column in a magnetic field. The magnetically labeled cells were retained on the column and were eluted as the positively selected cell fraction. The purity of B cells was more than 95\%. The purified B cells were cultured in PRMI 1640 medium containing 10\% FBS (Hyclone), 100U penicillin/ streptomycin (Gibco) in the absence or presence of the follow stimuli: 2.5 $\mu \mathrm{g} / \mathrm{ml} \mathrm{CpG} 2006$ (Sangon Biotech), $2.5 \mathrm{ug} / \mathrm{ml}$ AffiniPure F(ab') ${ }_{2}$ Fragment Goat Anti-Human IgA + IgG + IgM (H+L) (Jackson Immunoresearch Laboratories), 1ug/ml soluble CD40L (Peprotech) and 100U/ml IL-2 (Peprotech).

\section{Proliferation Assay}

Peripheral blood CD19+ B cells $\left(10^{4}\right.$ per well) were seeded in flat-bottom 96 well plates, and treated with or without irradiated UC-MSC $\left(10^{4}\right.$ per well) in PRMI 1640 medium containing 10\% FBS, 100U

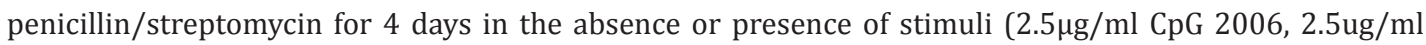
AffiniPure F(ab') ${ }_{2}$ Fragment Goat Anti-Human IgA + IgG + IgM (H+L), 1ug/ml soluble CD40L and 100U/ml (IL-2). The proliferation of purified B cells was measured using the cell proliferation BrdU ELISA kit (Roche Diagnostics) according to manufacturer's instructions. BrdU was added for the last $18 \mathrm{~h}$ of incubation. After fixation, the mouse monoclonal anti-BrdU-POD antibody was added. The immune complexes were revealed by the subsequent substrate reaction and add $1 \mathrm{M} \mathrm{H}_{2} \mathrm{SO}_{4}$ to stop the solution, then quantified by measuring the absorbance at $450 \mathrm{~nm}$ with a reference wavelength at $575 \mathrm{~nm}$ in a microliter plate reader.

\section{Enzyme-Linked Immunosorbent Assay}

Peripheral blood B cells $\left(10^{4}\right.$ per well) were seeded in flat-bottom 96 well plates, and cocultured with indicated doses of UC-MSC ( $10^{4}$ per well) for 4 or 7 days. Cell-free supernatants were collected and kept frozen at $80^{\circ} \mathrm{C}$ until assayed for cytokines concentration by enzyme-linked immunosorbent assays (ELISA). The $\mathrm{PGE}_{2}$ and IgA, IgG, IgM expressions were measured in the 7-day culturing cell-free supernatants, and IL-6 level were determined in the 4-day culturing cell-free supernatants by ELISA (Westang Biotech Co, Ltd., PR China, and Cayman Chemicals) following the supplier's instruction. 


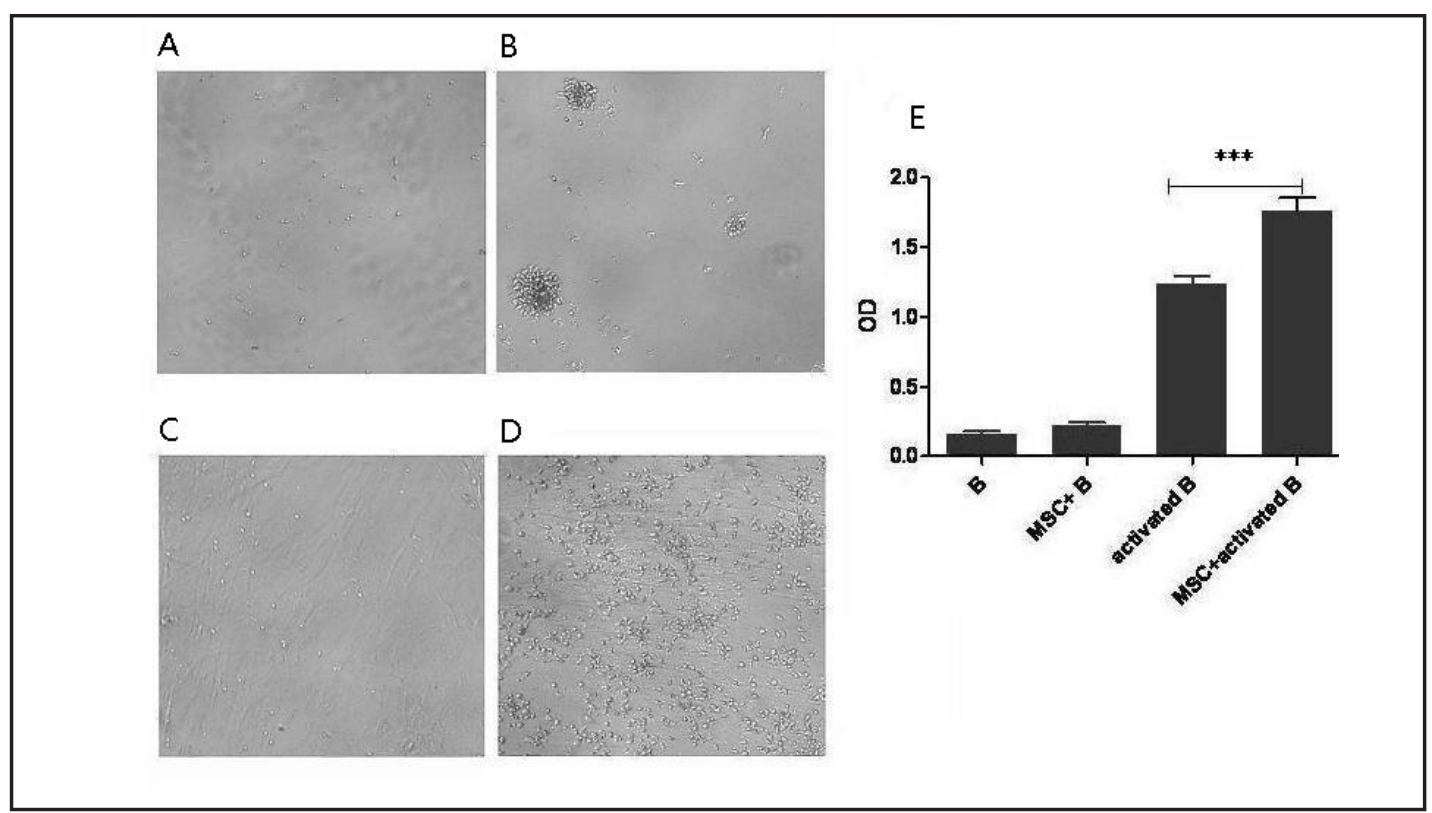

Fig. 1. UC-MSC promote Proliferation of activated purified peripheral blood B-cells. $10^{4}$ purified peripheral blood B-cells were treated with or without $10^{4}$ irradiated UC-MSC per well in 96-well plates for $90 \mathrm{~h}$, in the absent or in the present of the following stimuli: CpG 2006, rCD40L, anti-immunoglobulin antibodies and IL2. (A) without UC-MSC in the absent of stimuli; (B) without UC-MSC in the present of stimuli; (C) with UC-MSC in the absent of stimuli; (D) with UC-MSC in the present of stimuli; Magnification: 40×. (E) Proliferation data were evaluated by BrdU ELISA Kit. Each data represent the mean $\pm S E M$ of three independent experiments, each performed in triplicate. ${ }^{* * *} \mathrm{P}<0.001$.

\section{Immunization and ELISA assay for anti-TNP Abs}

Immunization and ELISA were performed as described by Franzoso et al. [24]. Briefly, female Eightweek-old male BALB/c mice were provided by the Institute of Experimental Animals, Chinese Academy of Medical Sciences. and immunized by a IP injection of $100 \mu \mathrm{g}$ 2,4,6-Trinitrophenyl Keyhole Limpet Hemocyanin (TNP-KLH), $50 \mu \mathrm{g}$ 2,4,6,-Trinitrophenyl lipopolysaccharide (TNP-LPS), and $25 \mu \mathrm{g}$ 2,4,6-Trinitrophenyl Ficoll (TNP-Ficoll) (all from Biosearch Technologies). Immediately after the antigen treatment, the mice were randomly divided into groups and injected intravenously with $1 \times 10^{6} \mathrm{BM}$-MSC in $100 \mu \mathrm{l}$ PBS per animal or with $100 \mu \mathrm{l}$ PBS alone. Sera were collected on day 7 and day 14 postimmunization. Serial dilutions of serum in PBS-Tween were placed in a TNP-BSA (Biosearch Technologies)-coated 96-well plate (ebiosicence) and refrigerated overnight. Following three washes with PBS-Tween, the plates were incubated for $1 \mathrm{~h}$ at RT with HRP-conjugated goat anti-mouse isotype-specific Abs (Southern Biotechnology Associates), and then incubated at RT for 30 minutes with the HRP substrate ABTS (ebiosicence) after another three washes. The reaction was stopped with $1 \mathrm{M} \mathrm{H}_{2} \mathrm{SO}_{4}$, and the absorbance was measured at $450 \mathrm{~nm}$.

\section{Statistical Analysis}

Data are presented as mean \pm SEM. When applicable, a Student's unpaired t-test and one-way ANOVA were used to determine significance, ${ }^{*} \mathrm{p}<0.05$, was considered to be statistically significant. Statistical analyses were performed using the GraphPad Prism software.

\section{Results}

UC-MSC promote proliferation of activated B-cells

UC-MSC could be isolated and expanded easily in large quantities in vitro and resemble BM-MSC in many respects. We examined the effects of human UC-MSC on purified human peripheral blood B cells in vitro. The purified peripheral blood B-cells were treated with or 


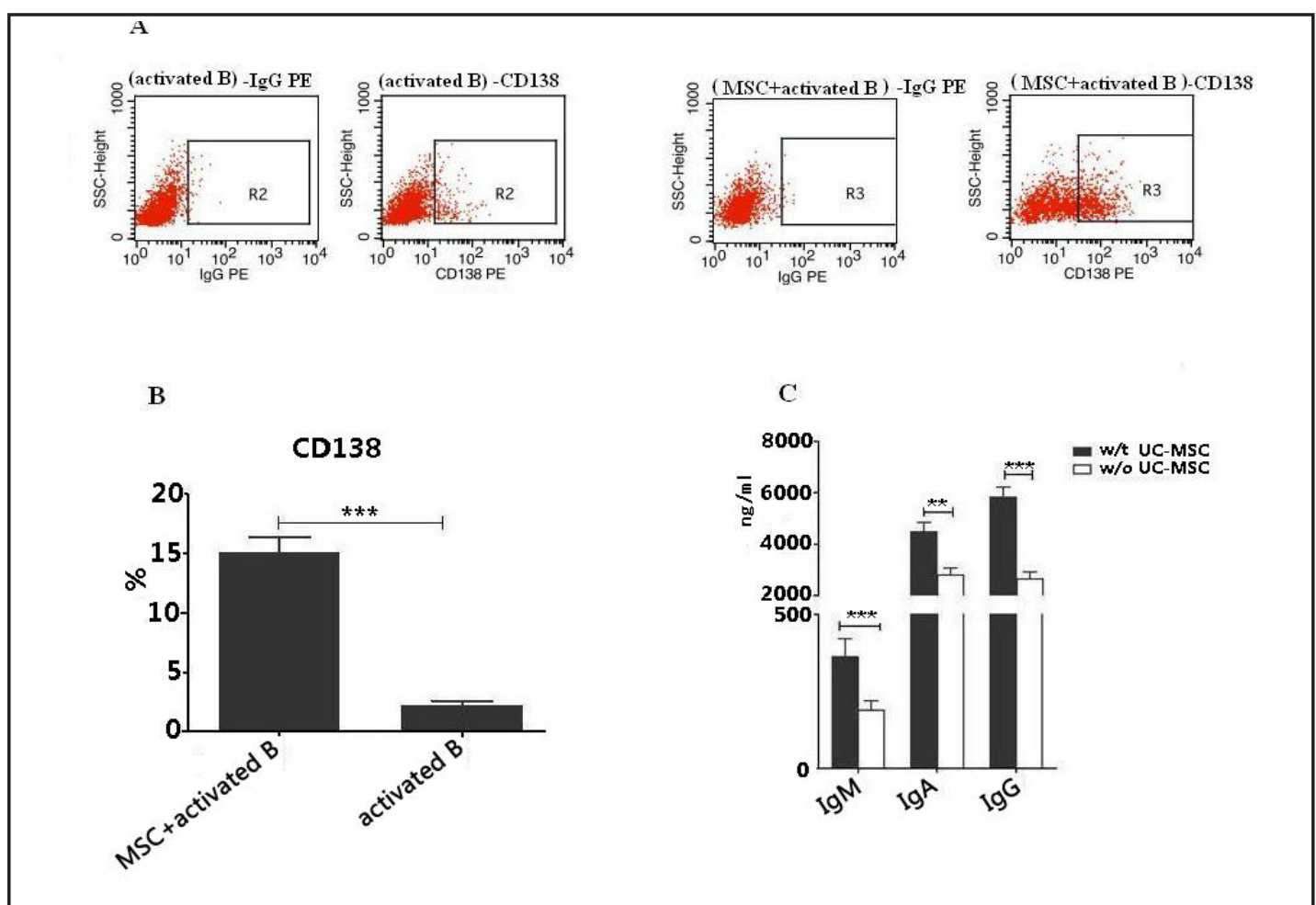

Fig. 2. UC-MSCs promote terminal differentiation and immunoglobulin production of Peripheral blood B-cells both in vitro and vivo. (A-B) Purified peripheral blood B cells were cultured for 7 days without or with irradiated UC-MSC at 1:1 ratios in the presence of $\mathrm{CpG}, \mathrm{rCD} 40 \mathrm{~L}$, anti-immunoglobulin antibodies, IL-2. After culture, B cells were stained with PE-CD138 mAb and analyzed by flow cytometry. Results obtained from 7 different experiments. ${ }^{* * *} \mathrm{P}<0.001$. (C) Immunoglobulin concentrations in 7 -day supernatants of purified peripheral blood B cells with or without UC-MSC. Each data represent the mean \pm SEM of 5-9 independent experiments. $\left({ }^{* * *} \mathrm{P}=0.0002\right.$ for $\operatorname{IgM} N=9 ;{ }^{* *} \mathrm{P}=0.0044$ for $\operatorname{IgA}, \mathrm{N}=5$; ${ }^{* * *} \mathrm{P}<0.0001$ for $\left.\operatorname{IgG}, \mathrm{N}=6\right)$.

without irradiated UC-MSC at ratio 1:1 for $90 \mathrm{~h}$ in the absence or presence of the stimuli (CpG 2006, rCD40L, anti-immunoglobulin antibodies and IL-2. As shown in Fig. 1, B cells do not proliferate without stimulation no matter cultured alone(Fig. 1A) or cocultured with UC-MSC (Fig. 1B) . B cells were activated by the stimuli and grow as cluster (Fig. 1C) while the increased number of B cells was observed and the cells were well spread when cocultured with UCMSC in the presence of stimili (Fig. 1D). Later proliferating cells number was calculated by Brdu ELISA (Fig. 1E), the OD in cocultured wells was not changed compared with B cells in the absence of the stimuli, while activated B cells had a significant increase in proliferation when cocultured with UC-MSC compared with activated B cells alone $(1.7592 \pm 0.09473$ versus $1.237 \pm 0.05293, \mathrm{P}<0.0001)$. Thus we demonstrate that UC-MSC drastically increase activated B cells proliferation in vitro.

MSC promote terminal differentiation and immunoglobulin production of B-cells in vitro

The effect of human UC-MSC on purified peripheral blood B cell differentiation was subsequently addressed by examining the expression of $\mathrm{CD} 138$, a special maker at the $\mathrm{B}$ cell terminal stage. The CD $138^{+}$B-cells is only $2.18 \% \pm 0.416$ when activated B cells were cultured alone for 7 days, and it went up to $15.08 \% \pm 1.305 \%(\mathrm{P}<0.001)$ when cocultured with irradiated UC-MSC at ratio 1:1 in the presence of $\mathrm{CpG}, \mathrm{rCD} 40 \mathrm{~L}$, anti-immunoglobulin antibodies and IL-2 (Fig. 2A and 2B). The increase of CD138 proved that UC-MSC promote B cell terminal differentiation.

In order to assess the immunomodulation of UC-MSC on immunoglobulin secretion, the immunoglobulin production in the 7-day culturing supernatants of purified peripheral 
Fig. 3. Soluble mediators mediate the immunomodulation of UC-MSC on purified peripheral blood B cells. $5 \times 10^{4}$ irradiated UC-MSC were plated onto the upper chamber of a 24 -well Transwell plate $2 \mathrm{~h}$ before the addition of $5 \times 10^{4} /$ well purified peripheral blood $\mathrm{B}$ cells in the presence of $\mathrm{CpG}, \mathrm{rCD} 40 \mathrm{~L}$, anti-immunoglobulin antibodies and IL-2. The cells were cultured for 4 days. The growth of B cells was observed by $40 \times$ Magnification. (A) Transwell (B) Purified activated peripheral blood B alone, and (C) addition of Brdu in the last $18 \mathrm{~h}$ to the culture and testing of the Brdu incoporation by Brdu ELISA. Data represent the mean \pm SEM of three independent experiments, each performed with UC-MSC from different donors, $* * * \mathrm{P}<0.0001$.

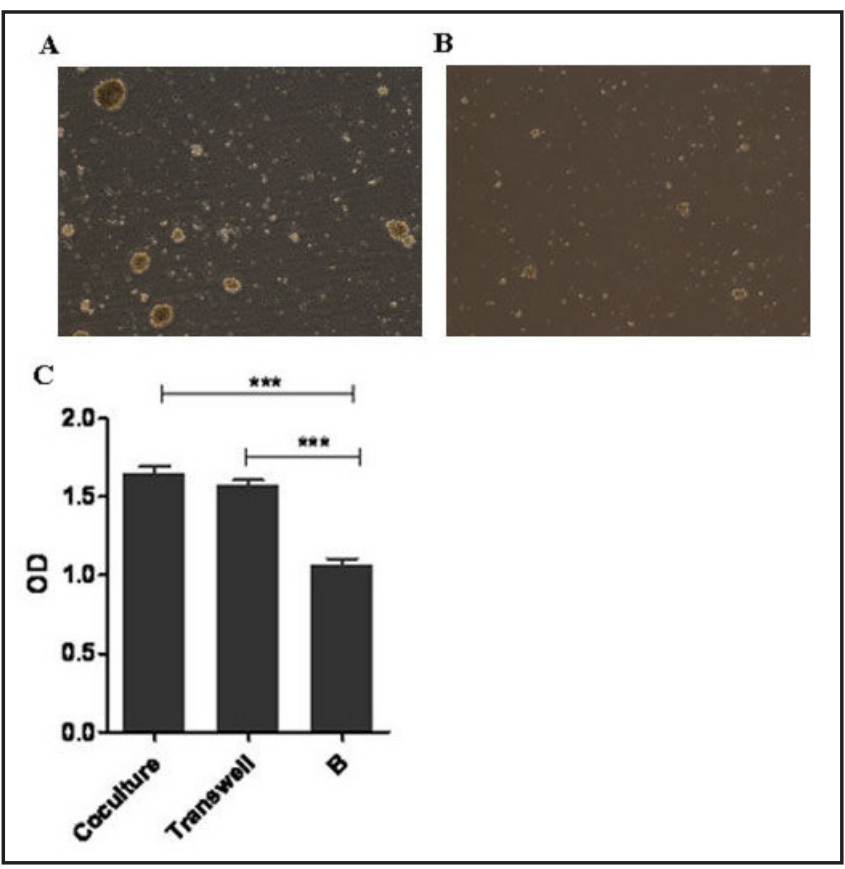

blood B cells without or with UC-MSC at a 1:1 ratio was assessed by ELISA. As shown in Fig. 2C, UC-MSC increased three kinds of immunoglobulin production (IgM: 1.8 fold, IgA: 1.6 fold, IgG: 2.2 fold). Thus, UC-MSCs promote the terminal differentiation and immunoglobulin production of B cells in vitro.

Immunomodulation of UC-MSC on purified peripheral blood B cells depends on soluble factors

Previous studies have shown that MSC exert immunosuppressive effects either through direct cell-cell contact or by soluble factors [8, 11, 25-29]. To determine this, we performed co-culture experiments using the transwell system in which purified peripheral blood B cells and UC-MSC were physically separated by a membrane permeable for soluble factors. Even in the absence of direct cell-cell contact, UC-MSC dramatically supported the growth of B cells observed in 40×Magnification (Fig. $3 \mathrm{~A}$ and $3 \mathrm{~B}$ ). In addition, We also tested B cells proliferation by Brdu ELISA, Brdu insert dramatically increased in transwell group than B cells group and There was no significant difference between cell-cell contact groups and transwell groups (Fig. 3C p<0.05), indicating that the immunomodulation of UC-MSC is largely mediated by soluble factors.

PGE2 but not IL-6 is an important soluble factor for UC-MSC-mediated immunomodulation

A number of soluble factors including TGF- $\beta$, IL-10, NO, PGE2, HLA-G have been proposed as possible mediators of MSC-mediated immune regulation [27-29]. PGE2 influences B cell Ig class-switch recombination, modulates B-cell differentiation [30-33]. Our previous data have demonstrated that PGE2-mediated mechanism by which UC-MSC exert their immunomodulatory effects on T cells [14, 34]. We assessed PGE2 and IL-6 in 4-day culturing cell-free supernatants, and we found PGE2 and IL-6 concentrations were both higher (PGE2:34.49 $\pm 5.792 \mathrm{ng} / \mathrm{ml}$, IL-6:33.68 $\pm 3.121 \mathrm{ng} / \mathrm{ml}$ ) in coculture system than UC-MSC alone (PGE2:17.84 $\pm 3.809 \mathrm{ng} / \mathrm{ml} \mathrm{P}=0.0339$, IL-6:19.70 $\pm 2.17 \mathrm{ng} / \mathrm{ml} \mathrm{P}=0.0072$ ) (Fig. 4A). Coculture experiments were performed in the presence or absence of specific inhibitors of PGE2 (indomethacin,10 mM) and neutralizing antibodies of IL-6. Indomethacin inhibited the percentage change in proliferation of B cells in coculture system from $34.4 \%$ to $22.1 \%$ (Fig. 4B), and indomethacin also inhibited percentage change in immunoglobulin production 
A

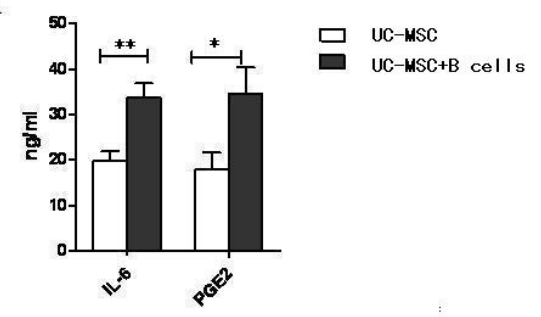

$\mathrm{C}$

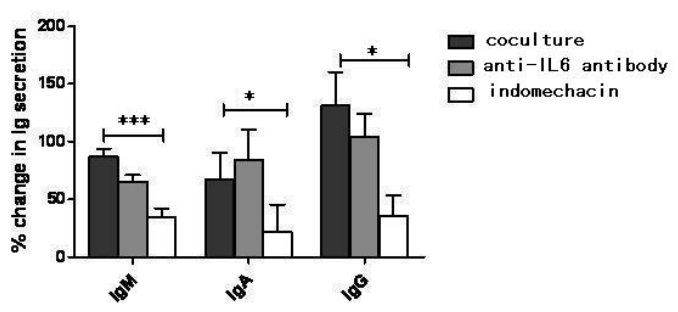

B

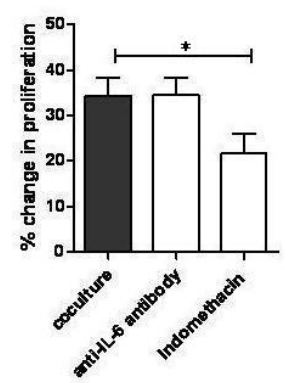

$\mathrm{D}$

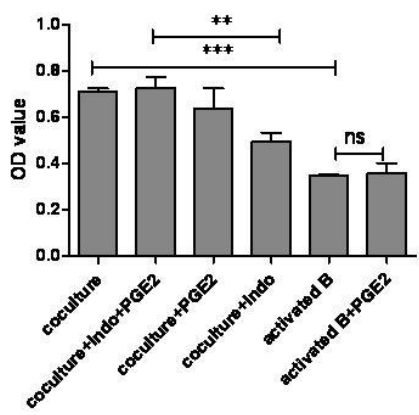

Fig. 4. PGE 2 but not IL- 6 is a soluble factor responsible for UC-MSC-mediated immunomodulation. $10^{4} /$ well irradiated UC-MSC were plated in 96 -well plate $2 \mathrm{~h}$ before the addition of $\mathrm{CpG}, \mathrm{rCD} 40 \mathrm{~L}$, anti-immunoglobulin antibodies, IL-2 -stimulated purified peripheral blood B cells. (A) 4-day culturing cell-free supernatants of UC-MSC alone and coculture system were collected to test IL-6 and PGE2 by ELISA. Data represent the mean \pm SEM of three independent experiments, each performed with UC-MSC from different donors ${ }^{*} \mathrm{P}<0.05$, ${ }^{* *} \mathrm{P}<0.01$. (B) Irradiated UC-MSC were co-cultured with purified peripheral blood $\mathrm{B}$ cells (at ratio of 1:1) activated by CpG, rCD40L, anti-immunoglobulin antibodies, IL-2 in the presence or absence of PGE2 inhibitors, indomethacin and neutralizing antibodies of IL-6, B cells proliferation was detected by Brdu ELISA at day 4. Three independent experiments were shown $* \mathrm{P}<0.05)$ and $(\mathrm{C}) 7$-day cell-free supernatants were collected to test IgM, IgA and IgG by ELISA. Data represent in three independent experiments ${ }^{*} \mathrm{P}<0.05$. (D) activated B cells were cultured with/without irradiated UC-MSC (at ratio of , B cells proliferation was detected by Brdu ELISA at day 4. Three independent experiments were shown ${ }^{* *} \mathrm{P}<0.01,{ }^{* * *} \mathrm{P}<0.0001$ ).

(IgM: $87.33 \%$ vs $34.9195 \% \mathrm{P}<0.001$, IgA: $67.65 \%$ vs $22.28 \% \mathrm{P}<0.05$, IgG: $131.5 \%$ vs $35.85 \%$ $\mathrm{P}<0.05$ ) (Fig. 4C). However, neutralizing antibodies of IL-6 only slightly reduce IgM and IgG production in coculture system, and there was no statistically significant difference (Fig. 4C). Moreover, neutralizing antibodies of IL-6 did not affect the proliferation and IgM production in coculture system. We also added exogenous PGE2 $(10 \mathrm{ng} / \mathrm{ml})$ and indomethacin $(10$ $\mathrm{mM}$ ) in the culture systems, and found that exogenous PGE2 could increase the B cells proliferation in coculture system while PGE2 secretion could be inhibited by indomethacin (Fig. 4D, P<0.0001). Exogenous PGE2 did not affect the proliferation of B cells (Fig. 4D, $\mathrm{P}>0.05$ ). Therefore MSCs derived PGE2 might cooperate with other soluble cytokines to regulate B-cell proliferation and differentiation.

BM-MSC promote immunoglobulin production of B-cells in vivo

$1 * 10^{6}$ murine BM-MSC were injected IP to mice immunized with TNP-KLH (T cell dependent antigen, TD-Ag), TNP-LPS (T cell independent antigen-I, TI-IAg), and TNP-Ficoll (T cell independent antigen-II TI-IIAg), and TNP-specific Abs were measured in serum at day 7 and day 14 post cell injection. The titers of TNP-specific IgM increased in TNP-LPS immunized mice 7 days after BM-MSC injection (Fig. 5A, $\mathrm{P}<0.05$ ), however, BM-MSC didn't 


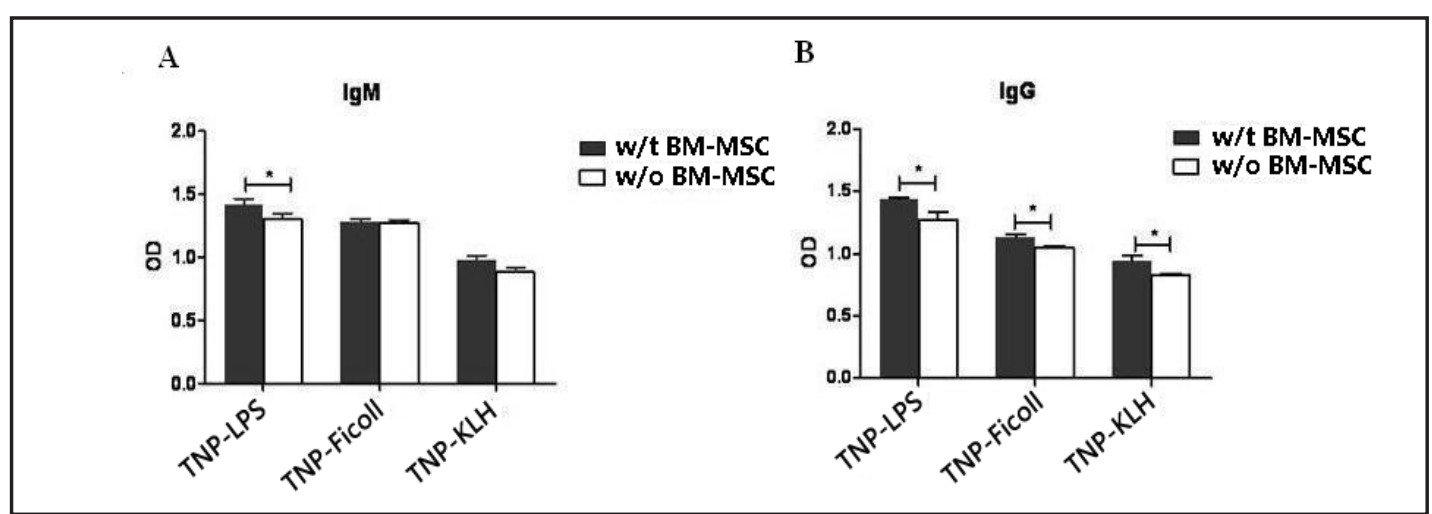

Fig. 5. Murine BM-MSCs promote immunoglobulin production in vivo. (A) $100 \mu \mathrm{g}$ TNP-KLH, $50 \mu \mathrm{g}$ TNPLPS and $25 \mu \mathrm{g}$ TNP-Ficoll were injected i.p. into separate groups of Bacb/C female mice with or without 106 BM-MSC per mouse. 7-day serum samples were collected for TNP-specific IgM. (5 samples from two independent experiments; ${ }^{*} \mathrm{p}<0.05$ ). (B) 14-day serum samples were collected for TNP-specific IgG. (5 samples from two independent experiments; * < 0.05). TNP-KLH: T cell dependent antigen TD-Ag; TNPFicoll: T cell independent antigen-II,TI-IIAg; TNP-LPS: T cell independent antigen-I, TI-Iag.

affect the TNP-specific IgM expression in TNP-KLH or TNP-Ficoll immunized mice ( $\mathrm{P}>0.05)$. the TNP-specific IgG-titer was elevated in immunized mice after 14 days treating with BMMSC (Fig. 5B, IgG of TNP-LPS enhanced from $1.436 \pm 0.01978$ to1.275 $\pm 0.06232 \mathrm{p}=0.0414$; IgG of TNP-KLH from $0.8253 \pm 0.01788$ to $0.9434 \pm 0.04361 \mathrm{p}=0.0155$; IgG of TNP-Ficoll from $1.135 \pm 0.02166$ to $1.051 \pm 0.01264 \mathrm{p}=0.0031$ ). These results clearly show that BM-MSC increased the immunoglobulin production in vivo.

\section{Discussion}

In this study, we demonstrated that MSC were able to support B cell proliferation and differentiation both in vitro and in vivo, and that the immunomodulation effect of MSC on B cells mainly depended on soluble factor PGE2 but not IL-6 secreted by UC-MSC. We further demonstrated that BM-MSC could promote production of antibodies in B cells in vivo.

UC-MSC could be isolated and expanded easily in large quantities in vitro and resemble bone marrow MSC (BM-MSC) in immunsuppression on T cell [16]. We examined the effects of UC-MSC on purified human peripheral blood B cells in vitro and found UC-MSC promoted the terminal differentiation of $\mathrm{B}$ cells to plasma cells and immunoglobulin production. MSC exert their immunomodulatory effects via cell-cell contact or soluble factors such as TGF- $\beta$, IL-10, NO, HLA-G and PGE2 . We have also detected the expression of soluble factors (PGE2, IL-6, IL10 , HLA-G, TGF- $\beta$ ) secreted by UC-MSC when UC-MSC were cocultured with activated B cells by real time PCR. We found that UC-MSC expressed IL-6, PGE2, HLA-G, and TGF-beta but not IL-10, and only IL-6 and PGE2 had statistically significant difference (data not shown). The results kept consistent with our previous data, which found only PGE2 and IL-6 increased when UC-MSC were cocultured with peripheral blood mononuclear cells. It has been known that PGE2 secreted by MSC affects immune cells such as T cells [14, 16, 34], NK [35] and DC [36]. PGE2 as an important regulator of the immune response shifts the balance towards a T helper type 2 response, and promotes memory cell formation [33, 37]. In addition, PGE2 affected B cell Ig class-switch recombination and modulated B-cell differentiation [30-33]. We found that the level of PGE2 was 2-fold higher in UC-MSC and B cells coculture system than UC-MSC alone, and that PGE2 inhibitor indomethacin partially but not completely (Fig. 4B and 4C) abolished the immunomodulation on the proliferation and immunoglobulin production of B cells. We found that exogenous PGE2 could increase the B cells proliferation in the MSC and B cells coculture systems (Fig .4D) while exogenous PGE2 did not play any role in B cells cultured alone. Some studies had demonstrated PGE2 strongly enhanced isotype 
differentiation to IgE and IgG in the presence of IL-4 [32], So we think that the exogenous PGE2 alone can not substitute the effects of MSCs on B cells, but give rise to a critical role of MSCs. These results indicated that PGE2 only partially mediated the immunomodulation effect of MSCs on B cells. PGE2 might cooperate with other MSC derived soluble cytokines to regulate B-cell proliferation and terminal differentiation. IL-6 was another soluble factor mediated the immunomodulation of MSC especially on DCs [38]. We also found that IL-1 $\beta$ promoted the secretion of IL-6 by UC-MSC via JNK and NF- $\kappa$ B signaling pathway. However IL-6 is not directly associated with the immunoinhibitory activity UC-MSC on CD4 ${ }^{+} \mathrm{T}$ cell [39]. IL-6 was originally isolated and cloned as a B-cell differentiation factor that induced terminal B-cell differentiation and supported the production of immunoglobulin G (IgG) $[40,41]$ We observed that although the level of IL- 6 was higher in coculture system, the neutralizing antibodies to IL- 6 did not affect the immunomodulation on B cells. In conclusion, we presumed that IL- 6 does not participate in the immunoinhibitory activity of UC-MSC on B cells.

We then tested if MSC modulate immunoglobulin production in vivo. We firstly injected human UC-MSC into BALB/c mice, and we found that mice spleen was dramatically increased, so we presumed allogeneic MSC possessed immunogenicity. In order to test the effect of MSC on B cells, we used female bone marrow MSC of BALB/c mice to observe the effect on immunoglobulin production with two type different antigens. Mice BM-MSC supported both the antibodies production of both TD-Ag (TNP-KLH) and TI-Ag (TI-I Ag:TNP-LPS, TI-II Ag:TNP-Ficoll) in vivo. BM-MSC promoted IgM antibodies production of TNP-LPS (shown in Fig. 5A) on day 7, and TNP-LPS is a kind of TI-I antigens which can activate the innate immunity at the early time. BM-MSC also increased the IgG antibodies production of both $\mathrm{T}$ dependent and independent antigens (shown in Fig. 5B). We demonstrated that BMMSC supported immunoglobulin production in normal mice in vivo for the first time, and it suggest an important interaction between MSC and humoral immunity.

These data are in line with a previous observation made by Traggiai et al. [22], who reported an increase in proliferation and differentiation into plasma cells of transitional and naïve B cells isolated from peripheral blood both healthy human and systemic lupus erythematosus patient mediated by MSC in vitro. Youd and colleagues also demonstrated that co-culturing MSC with plasma cells purified from NZB/W mice led to an increase in immunoglobulin G antibody production, and suggested that MSC therapy may not be beneficial in Th2-type and B cell-driven diseases [21]. And our results kept consistent with the studies which demonstrated MSC [21] and PGE2 [33] shifting the balance towards a T helper type 2 response and humoral immunity. However, our present data were in contrast with a previous report describing MSC-mediated inhibition of proliferation and differentiation into immunoglobulin secretion cells of human peripheral B cells by Anna Corcione [42] and other teams [43-46]. And Nan Che also found human UC-MSC suppressed mice spleen B-cell proliferation and differentiation. The discrepancies might reflect differences in B cells source and purification procedures, culture conditions, and timing of analysis. We emphasize that different culture conditions containing B cell active factors and B cell secretion factors may polarize MSC to have different immunomodulation activities on B cells. For example, IFN- $\gamma$ promoted the immunosuppressive capacity of MSCs [47] and overruled the growth promoting effect of MSC on primary purified follicular lymphoma B cells [48]. We compared the culture conditions between Anna Corcione [42] and Traggiai E [22] and found that IL-4 could partly reverse the immunomodulation of UC-MSC on B cell (data not shown) while IL-4 stimulated B activity and class switching. The microenvironment plays a determinative role in the immonomodulation of MSCs. Further study will be needed to determine which inflammatory factors trigger the different immunomodulation of MSCs. In addition, we presume that the modulation of MSC on B cell is why MSC play a double-edged sword in some autoimmunity diseases.

In conclusion, we have shown that UC-MSC promoted the proliferation and terminal differentiation of B cells both in vitro and in vivo, and the promoting effect partially depends on PGE2 but not IL-6. Our study castes important questions on UC-MSC as a therapeutic tool 
in autoimmune diseases especially TH2 type autoimmune diseases in which B-cell activation is crucially implicated in the pathogenesis of the disease. However, further studies are still necessary to compare the immunomodulation of MSC on B cells activities in TH1-type autoimmune diseases and TH2-type autoimmune diseases.

\section{Disclosure Statement}

The authors declare no competing financial interests.

\section{Acknowledgements}

We thank Ke Chen, Ding Wang and for excellent technical assistance. This study was supported by the 863 project (Grant no. 2011AA020118) and the 973 program of China 2011 CB964800 (Grant no. 2011CB964802) from the Ministry Science \& Technology of China.

\section{Reference}

1 Friedenstein AJ, Chailakhjan RK, Lalykina KS: The development of fibroblast colonies in monolayer cultures of guinea-pig bone marrow and spleen cells. Cell Tissue Kinet 1970;3:393-403.

-2 Zuk PA, Zhu M, Mizuno H, Huang J, Futrell JW, Katz AJ, Benhaim P, Lorenz HP, Hedrick MH: Multilineage cells from human adipose tissue: Implications for cell-based therapies. Tissue Eng 2001;7:211-228.

- B Bieback K, Kern S, Kluter H, Eichler H: Critical parameters for the isolation of mesenchymal stem cells from umbilical cord blood. Stem Cells 2004;22:625-634.

- 4 In 't Anker PS, Scherjon SA, Kleijburg-van der Keur C, de Groot-Swings GM, Claas FH, Fibbe WE, Kanhai $\mathrm{HH}$ : Isolation of mesenchymal stem cells of fetal or maternal origin from human placenta. Stem Cells 2004;22:1338-1345.

-5 Lu LL, Liu YJ, Yang SG, Zhao QJ, Wang X, Gong W, Han ZB, Xu ZS, Lu YX, Liu D, Chen ZZ, Han ZC: Isolation and characterization of human umbilical cord mesenchymal stem cells with hematopoiesis-supportive function and other potentials. Haematologica 2006;91:1017-1026.

6 In 't Anker PS, Scherjon SA, Kleijburg-van der Keur C, Noort WA, Claas FH, Willemze R, Fibbe WE, Kanhai $\mathrm{HH}$ : Amniotic fluid as a novel source of mesenchymal stem cells for therapeutic transplantation. Blood 2003;102:1548-1549.

7 In 't Anker PS, Noort WA, Scherjon SA, Kleijburg-van der Keur C, Kruisselbrink AB, van Bezooijen RL, Beekhuizen W, Willemze R, Kanhai HH, Fibbe WE: Mesenchymal stem cells in human second-trimester bone marrow, liver, lung, and spleen exhibit a similar immunophenotype but a heterogeneous multilineage differentiation potential. Haematologica 2003;88:845-852.

8 Nauta AJ, Fibbe WE: Immunomodulatory properties of mesenchymal stromal cells. Blood 2007;110:34993506.

9 Aggarwal S, Pittenger MF: Human mesenchymal stem cells modulate allogeneic immune cell responses. Blood 2005;105:1815-1822.

10 Zappia E, Casazza S, Pedemonte E, Benvenuto F, Bonanni I, Gerdoni E, Giunti D, Ceravolo A, Cazzanti F, Frassoni F, Mancardi G, Uccelli A: Mesenchymal stem cells ameliorate experimental autoimmune encephalomyelitis inducing t-cell anergy. Blood 2005;106:1755-1761.

11 Choi JJ, Yoo SA, Park SJ, Kang YJ, Kim WU, Oh IH, Cho CS: Mesenchymal stem cells overexpressing interleukin-10 attenuate collagen-induced arthritis in mice. Clin Exp Immunol 2008;153:269-276.

-12 Sun L, Akiyama K, Zhang H, Yamaza T, Hou Y, Zhao S, Xu T, Le A, Shi S: Mesenchymal stem cell transplantation reverses multiorgan dysfunction in systemic lupus erythematosus mice and humans. Stem Cells 2009;27:1421-1432.

13 Jones BJ, McTaggart SJ: Immunosuppression by mesenchymal stromal cells: From culture to clinic. Exp Hematol 2008;36:733-741. 


\section{Cellular Physiology $\quad$ Cell Physiol Biochem 2012;30:1526-1537 and Biochemistry

14 Wang D, Chen K, Du WT, Han ZB, Ren H, Chi Y, Yang SG, Bayard F, Zhu D, Han ZC: Cd14+ monocytes promote the immunosuppressive effect of human umbilical cord matrix stem cells. Exp Cell Res 2010;316:2414-2423.

15 Sun J, Han ZB, Liao W, Yang SG, Yang Z, Yu J, Meng L, Wu R, Han ZC: Intrapulmonary delivery of human umbilical cord mesenchymal stem cells attenuates acute lung injury by expanding cd4+cd $25+$ forkhead boxp3 (foxp3)+ regulatory t cells and balancing anti- and pro-inflammatory factors. Cell Physiol Biochem 2011;27:587-596.

16 Chen K, Wang D, Du WT, Han ZB, Ren H, Chi Y, Yang SG, Zhu D, Bayard F, Han ZC: Human umbilical cord mesenchymal stem cells huc-mscs exert immunosuppressive activities through a pge(2)-dependent mechanism. Clin Immunol 2010; 135:448-458.

17 Djouad F, Fritz V, Apparailly F, Louis-Plence P, Bony C, Sany J, Jorgensen C, Noel D: Reversal of the immunosuppressive properties of mesenchymal stem cells by tumor necrosis factor alpha in collageninduced arthritis. Arthritis Rheum 2005;52:1595-1603.

18 Jurewicz M, Yang S, Augello A, Godwin JG, Moore RF, Azzi J, Fiorina P, Atkinson M, Sayegh MH, Abdi R: Congenic mesenchymal stem cell therapy reverses hyperglycemia in experimental type 1 diabetes. Diabetes 2010;59:3139-3147.

19 Zheng ZH, Li XY, Ding J, Jia JF, Zhu P: Allogeneic mesenchymal stem cell and mesenchymal stem celldifferentiated chondrocyte suppress the responses of type ii collagen-reactive t cells in rheumatoid arthritis. Rheumatology (Oxford) 2008;47:22-30.

-20 Roord ST, de Jager W, Boon L, Wulffraat N, Martens A, Prakken B, van Wijk F: Autologous bone marrow transplantation in autoimmune arthritis restores immune homeostasis through cd4+cd25+foxp3+ regulatory t cells. Blood 2008;111:5233-5241.

21 Youd M, Blickarz C, Woodworth L, Touzjian T, Edling A, Tedstone J, Ruzek M, Tubo R, Kaplan J, Lodie T: Allogeneic mesenchymal stem cells do not protect nzbxnzw f1 mice from developing lupus disease. Clin Exp Immunol 2010;161:176-186.

22 Traggiai E, Volpi S, Schena F, Gattorno M, Ferlito F, Moretta L, Martini A: Bone marrow-derived mesenchymal stem cells induce both polyclonal expansion and differentiation of b cells isolated from healthy donors and systemic lupus erythematosus patients. Stem Cells 2008;26:562-569.

23 Dorner T, Jacobi AM, Lipsky PE: B cells in autoimmunity. Arthritis Res Ther 2009;11:247.

24 Franzoso G, Carlson L, Poljak L, Shores EW, Epstein S, Leonardi A, Grinberg A, Tran T, Scharton-Kersten T, Anver M, Love P, Brown K, Siebenlist U: Mice deficient in nuclear factor (nf)-kappa b/p52 present with defects in humoral responses, germinal center reactions, and splenic microarchitecture. J Exp Med 1998;187:147-159.

25 Najar M, Raicevic G, Boufker HI, Fayyad Kazan H, De Bruyn C, Meuleman N, Bron D, Toungouz M, Lagneaux L: Mesenchymal stromal cells use pge2 to modulate activation and proliferation of lymphocyte subsets: Combined comparison of adipose tissue, wharton's jelly and bone marrow sources. Cell Immunol 2010;264:171-179.

-26 Di Nicola M, Carlo-Stella C, Magni M, Milanesi M, Longoni PD, Matteucci P, Grisanti S, Gianni AM: Human bone marrow stromal cells suppress t-lymphocyte proliferation induced by cellular or nonspecific mitogenic stimuli. Blood 2002;99:3838-3843.

27 Meisel R, Zibert A, Laryea M, Gobel U, Daubener W, Dilloo D: Human bone marrow stromal cells inhibit allogeneic t-cell responses by indoleamine 2,3-dioxygenase-mediated tryptophan degradation. Blood 2004;103:4619-4621.

28 Sato K, Ozaki K, Oh I, Meguro A, Hatanaka K, Nagai T, Muroi K, Ozawa K: Nitric oxide plays a critical role in suppression of t-cell proliferation by mesenchymal stem cells. Blood 2007;109:228-234.

-29 Jarvinen L, Badri L, Wettlaufer S, Ohtsuka T, Standiford TJ, Toews GB, Pinsky DJ, Peters-Golden M, Lama VN: Lung resident mesenchymal stem cells isolated from human lung allografts inhibit t cell proliferation via a soluble mediator. J Immunol 2008;181:4389-4396.

30 Ryan EP, Malboeuf CM, Bernard M, Rose RC, Phipps RP: Cyclooxygenase-2 inhibition attenuates antibody responses against human papillomavirus-like particles. J Immunol 2006;177:7811-7819.

-31 Roper RL, Brown DM, Phipps RP: Prostaglandin e2 promotes b lymphocyte ig isotype switching to ige. J Immunol 1995;154:162-170.

32 Roper RL, Conrad DH, Brown DM, Warner GL, Phipps RP: Prostaglandin e2 promotes il-4-induced ige and igg1 synthesis. J Immunol 1990;145:2644-2651.

33 Roper RL, Graf B, Phipps RP: Prostaglandin e2 and camp promote b lymphocyte class switching to igg1. Immunol Lett 2002;84:191-198. 


\section{Cellular Physiology $\quad$ Cell Physiol Biochem 2012;30:1526-1537 and Biochemistry

-34 Cui L, Yin S, Liu W, Li N, Zhang W, Cao Y: Expanded adipose-derived stem cells suppress mixed lymphocyte reaction by secretion of prostaglandin e2. Tissue Eng 2007;13:1185-1195.

-35 Spaggiari GM, Capobianco A, Abdelrazik H, Becchetti F, Mingari MC, Moretta L: Mesenchymal stem cells inhibit natural killer-cell proliferation, cytotoxicity, and cytokine production: Role of indoleamine 2,3-dioxygenase and prostaglandin e2. Blood 2008;111:1327-1333.

-36 Spaggiari GM, Abdelrazik H, Becchetti F, Moretta L: Mesenchymal stem cells (msc) inhibit monocytederived dendritic cell $(\mathrm{dc})$ maturation and function by selectively interfering with the generation of immature dcs: Central role of msc-derived prostaglandin e2. Blood 2009;113:6576-6583.

37 Betz M, Fox BS: Prostaglandin e2 inhibits production of th1 lymphokines but not of th2 lymphokines. J Immunol 1991;146:108-113.

38 Djouad F, Charbonnier LM, Bouffi C, Louis-Plence P, Bony C, Apparailly F, Cantos C, Jorgensen C, Noel D: Mesenchymal stem cells inhibit the differentiation of dendritic cells through an interleukin-6-dependent mechanism. Stem Cells 2007;25:2025-2032.

39 Wang D, Ji YR, Chen K, Du WT, Yang ZX, Han ZB, Chi Y, Liang L, Bayard F, Han ZC: Il-6 production stimulated by cd14 monocytes-paracrined il-1beta does not contribute to the immunosuppressive activity of human umbilical cord mesenchymal stem cells. Cell Physiol Biochem 2012;29:551-560.

40 Yoshizaki K, Nakagawa T, Fukunaga K, Tseng LT, Yamamura Y, Kishimoto T: Isolation and characterization of b cell differentiation factor (bcdf) secreted from a human b lymphoblastoid cell line. J Immunol 1984;132:2948-2954.

41 Maeda K, Mehta H, Drevets DA, Coggeshall KM: Il-6 increases b-cell igg production in a feedforward proinflammatory mechanism to skew hematopoiesis and elevate myeloid production. Blood;115:4699-4706.

-42 Corcione A, Benvenuto F, Ferretti E, Giunti D, Cappiello V, Cazzanti F, Risso M, Gualandi F, Mancardi GL, Pistoia V, Uccelli A: Human mesenchymal stem cells modulate b-cell functions. Blood 2006;107:367-372.

43 Bochev I, Elmadjian G, Kyurkchiev D, Tzvetanov L, Altankova I, Tivchev P, Kyurkchiev S: Mesenchymal stem cells from human bone marrow or adipose tissue differently modulate mitogen-stimulated b-cell immunoglobulin production in vitro. Cell Biol Int 2008;32:384-393.

44 Comoli P, Ginevri F, Maccario R, Avanzini MA, Marconi M, Groff A, Cometa A, Cioni M, Porretti L, Barberi W, Frassoni F, Locatelli F: Human mesenchymal stem cells inhibit antibody production induced in vitro by allostimulation. Nephrol Dial Transplant 2008;23:1196-1202.

45 Asari S, Itakura S, Ferreri K, Liu CP, Kuroda Y, Kandeel F, Mullen Y: Mesenchymal stem cells suppress b-cell terminal differentiation. Exp Hematol 2009;37:604-615.

-46 Che N, Li X, Zhou S, Liu R, Shi D, Lu L, Sun L: Umbilical cord mesenchymal stem cells suppress b-cell proliferation and differentiation. Cell Immunol 2012,274:46-53.

-47 Ryan JM, Barry F, Murphy JM, Mahon BP: Interferon-gamma does not break, but promotes the immunosuppressive capacity of adult human mesenchymal stem cells. Clin Exp Immunol 2007;149:353363.

48 Maby-El Hajjami H, Ame-Thomas P, Pangault C, Tribut O, DeVos J, Jean R, Bescher N, Monvoisin C, Dulong J, Lamy T, Fest T, Tarte K: Functional alteration of the lymphoma stromal cell niche by the cytokine context: Role of indoleamine-2,3 dioxygenase. Cancer Res 2009;69:3228-3237. 